\title{
Puesta en valor de la Casa Hacienda Punchauca
}

\author{
Rolando Arciga Soto \\ rolando.arciga@unmsm.edu.pe \\ Universidad Nacional Mayor de San Marcos
}

\section{RESUMEN:}

Punchauca presenta una larga historia muy anterior a la conferencia entre el general don José de San Martín y el virrey José de la Serna de 1821, posteriormente la hacienda pasaría en las últimas décadas por un periodo de abandono, que significó la destrucción de su complejo agrario, el fin de su entorno agrícola, la desaparición de la sociedad rural y el deterioro de su casa hacienda. Aunque en la actualidad las iniciativas de la puesta en valor están encaminadas, se tendrá que escoger un modelo de gestión adecuado, darle el uso más conveniente y hacer que la población local se sienta identificada con la hacienda. El propósito del presente trabajo es mostrar un diagnóstico sobre estos diferentes aspectos.

Palabras Clave: Punchauca; Arquitectura colonial; Puesta en valor; Conservación; Restauración.

\section{Assessing Cultural Heritage of Casa Hacienda Punchauca}

\begin{abstract}
:
The Punchauca hacienda had already a long history previous to the Conference held between General José de San Martín and the Viceroy José de la Serna in 1821. Later on the hacienda went through a period of abandonment, which meant the destruction of its agrarian complex, the end of their agricultural fields, the disappearance, and the deterioration of its infraestructure. Although the initiatives about assessing its cultural importance are currently underway, it needs to establish its particular model of adequate management, its most convenient use. Also, it is necessary to work on how to make local people to identify themselves with this cultural patrimony. Therefore, this article attempts to present a diagnosis about such aspects.
\end{abstract}

Keywords: Punchauca;Colonial architecture; Value enhancement;Conservation; Restoration.

(C) Los autores. Este artículo es publicado por ISHRA, Revista del Instituto Seminario de Historia Rural Andina de la Facultad de Ciencias Sociales de la Universidad Nacional Mayor de San Marcos. Este es un artículo de acceso abierto, distribuido bajo los términos de la licencia Creative Commons Atribucion - No Comercia Compartir Igual 4.0 Internacional. (http://creativecommons.org/licenses/by-nc-sa/4.0/) que permite el uso no comercial, distribución y reproducción en cualquier medio, siempre que la obra original sea debidamente citada. 


\section{Introducción}

La zona Punchauca ha tenido actividad cultural desde época muy temprana como muestra de ello han quedado sitios arqueológicos cercanos y un sistema de irrigación basado en agua de puquiales y del río para alimentar a su zona agrícola milenaria. Pasada la conquista del Perú el control de la tierra pasó de los curacas Francisco Yangue y Cristóbal Yangue al primer alcalde de la ciudad de Lima Nicolás de Rivera en el año 1543, es así como las tierras cambiaron de propietario durante el transcurso de los siglos, siendo sus dueños más ilustres los primeros marqueses de Santa María de Pacoyán. El título nobiliario fue creado por Real Cédula de Felipe V el 01 de noviembre de 1716 en favor de Martín José Muñoz Mudarra de la Serna por sus contribuciones a la Guerra de Sucesión Española. Otro dueño ilustre fue Lucas Vergara y Rosas quien fue caballero de la Orden Militar Religiosa de Santiago, el cual a fines del siglo XVIII cambió el nombre de la hacienda a Santiago de Punchauca. Con el inicio del siglo XIX sucedería un hecho trascendental en la casa hacienda que fue la Conferencia de Punchauca entre el general don José de San Martín y el virrey José de la Serna para ver la Independencia de Perú. Fue así como la Casa Hacienda Punchauca se convirtió en un escenario más del proceso de independencia de América Española. Con la llegada de la República, la Hacienda Punchauca siguió pasando a manos de personajes destacados como políticos, grandes comerciantes y empresarios; hasta que en el año 1933 se creó la Compañía Agrícola Punchauca S. A. (Capsa), siendo después formado el Sindicato de Inversiones Rústicas y Urbanas S. A. (Sirusa). Posteriormente, en el año 1974, los campesinos obtuvieron el beneficio de ser considerados en la Reforma Agraria fundando una cooperativa y siendo después las tierras parceladas. Como vemos la zona de Punchauca es relevante debido a que está relacionada con todas las etapas por las que ha pasado el Perú: Prehispánica, Colonia y República. Profundizar el estudio de la Hacienda Punchauca es importante debido a que nos puede brindar información para la época de la Colonia y República sobre: la producción agrícola y ganadera; también sobre la sociedad rural. La importancia de la arquitectura de la Casa Hacienda Punchauca radica en ser un ejemplo rural de tipo casa hacienda de la época de la Colonia, del cual quedan pocos en el valle del río Chillón, solo recibiendo modificaciones significativas en el siglo XIX. Por otro lado, lo que queda del complejo agrario es un tipo de infraestructura antigua que ya ha desaparecido en otros lugares del valle; además, un estudio de la arquitectura nos dará un respaldo para realizar una correcta intervención (conservación, restauración o puesta en valor). La justificación para la intervención de Casa Hacienda Punchauca y su complejo agrícola radica en su valor histórico y arquitectónico; además, el entorno agrícola que rodea a estos es parte de su contexto y el cual siempre se debe tomar en cuenta para hacer una lectura e interpretación adecuada del bien, debiendo ser mantenido al igual. En la actualidad la restauración de la Casa Hacienda Punchauca está encaminada, pero tendríamos que tener en cuenta que no podemos reducir las acciones que necesitan ejecutarse a solo tener este escenario histórico en buenas condiciones para el 28 de julio del 2021, fecha en la cual el Perú cumplirá 200 años de vida republicana; es necesaria una puesta en valor en el monumento que tenga un modelo de gestión acorde, que se vea el uso más adecuado y que la población local participe.

\section{Ubicación}

Punchauca se ubica en el distrito de Carabayllo, provincia y región de Lima, en el Km. 25.2 de la carretera a Canta, a una altura de 257.33 metros sobre el nivel del mar (m.s.n.m.) y cerca del río Chillón. Sus coordenadas UTM en el sistema WGS 84, son: 8783838.0000 Norte y 390750.0000 Este. En base a la clasificación de zonas geográficas hecha por Javier Pulgar Vidal para el Perú, Punchauca se encontraría en la chala. (Pulgar, 1941). Sobre los límites de la zona se tiene que tener en cuenta los antiguos y los actuales. Sobre los límites antiguos que tenía la Hacienda 
Punchauca en la época de la Colonia revisando el trabajo de Ambrosio Cerdán de Landa Simón Pontero (quien fuera parte del consejo del Rey de España, oidor en la Real Audiencia de los Reyes, individuo de la Real Academia Española de la Historia, y de la Sociedad de Amantes del País), se puede decir que limitaba al suroeste con la Hacienda Huacoy o San Humberto, al sureste con los cerros o estribaciones andinas, al noreste con Caballero y al noroeste pasando el río Chillón se encontraba Cuchicorral. (Cerdán, 1793). Sobre los límites actuales habría que mencionar que lo que fuera el complejo agrario de la hacienda dio paso a un centro poblado el cual mantuvo el nombre original y que en la zona agrícola aparecieron nuevas zonas pobladas; el «Centro Poblado de Punchauca» al sur colinda con la zona poblada de «Torre Blanca», al sureste con la urbanización el «Doral de Torre Blanca II» y la «Nueva Urbanización Torre Blanca» al este en la ladera de los cerros con el «Asentamiento Humano Las Lomas de Torre Blanca Alta» y al norte la planta de tratamiento Agua Azul.

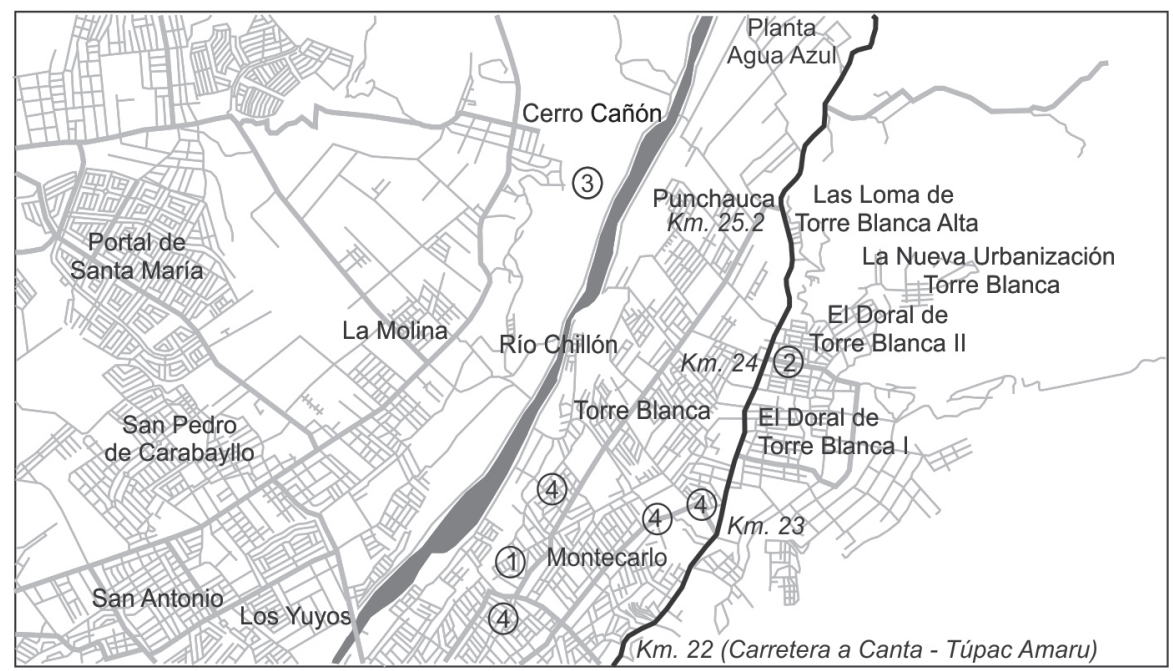

Figura 1. Croquis de ubicación de Punchauca dentro de Carabayllo. Se aprecia también los sitios arqueológicos cercanos a la casa hacienda: 1- Templo en forma de "U“ Huacoy, 2- Ex Establo de Punchauca, 3 - Cerro Cañon, 4 - Montículos.

\section{Historia}

En la zona de Punchauca y cerca de esta existieron y existen actualmente un gran número de sitios arqueológicos, entre ellos podemos mencionar:

El Templo en forma de «U» de Huacoy, el cual se encuentra a $150 \mathrm{~m}$. al sur del cauce del río Chillón en los terrenos de la ex-Hacienda de Huacoy o San Humberto que antiguamente colindó con la de Punchauca. Fue construido durante el Periodo Inicial (1800 a.C a 1000 a.C) y el Horizonte Temprano (1000 a.C. a 200 a.C.) usando adobes semicirculares y piedras. El montículo central presenta un vestíbulo justo en la base y sobre la plaza, este se conecta con un atrio en la parte superior. El brazo nor-oeste se compone de unos tres montículos y el brazo nor-este tiene cuatro. El sitio fue estudiado por el arqueólogo Hugo Ludeña Restaure quien realizó su tesis sobre el sitio. (Ludeña, 1973). En el ex-Establo de Punchauca que se encontraba en el km 24 para el lado oeste de la carretera a Canta se identificaron sitios del Periodo Intermedio Temprano (200 a.C. a 700 d.C.), estos fueron registrados por el Padre Villar Córdova en su trabajo «Culturas Prehispánicas del Departamento de Lima». (Villar, 1935). En la ladera occidental del Cerro Cañón que se encuentra en la zona de la antigua Hacienda Chuchicorral que está en la otra margen del río Chillón a la altura de Punchauca, se mencionó ocupación de los Periodos Intermedio Temprano (200 a.C a 700 d.C.) e Intermedio Tardío (1000 d.C. a 1440 d.C.) en el artículo de Silva Sifuentes llamado «Una aproximación al periodo Formativo en el valle del Chillón». (Silva, 
1998). Por último en zonas cercanas se hace registro de dos sitios del Periodo Intermedio Tardío (1000 d.C. a 1440 d.C.), el primero estaba compuesto por 11 montículos alrededor del templo en «U» de Huacoy construidos con cantos rodados, relleno y piedras; y el segundo ubicado en el kilometro 23 de la Carretera a Canta, hecho con muros de tapial de $3.5 \mathrm{~m}$ de alto, estos se encuentran descritos en el Inventario Ford-UNI (Williams, Palacios, Pérez, Guerrero y Palacios, 1989)

Sobre el emplazamiento de la actual Casa Hacienda Punchauca algunos investigadores como Edgar Quispe Pastrana indican que la plataforma o altillo en donde se encuentra ocultaría restos de la época prehispánica. Edgar Quispe Pastrana menciona en su trabajo lo siguiente:

Punchauca fue una huaca, es decir fue un lugar sagrado. Su nombre deriva del quechua: Punchau significa "el día claro, con sol"y huaca es "lugar sagrado"; es decir, es "el lugar donde se adora al día (sol)". Su edificación correspondería al Período Intermedio Tardio, época en que dominó el Señorío Colli, aunque se presume también que puede estar relacionado con los Incas debido a que aquí rendían culto al sol (Quispe, 2013, p. 7).

El planteamiento de que la CasaHaciendaPunchauca fue construida sobre un sitio prehispánico, si lo comparamos con otras casas haciendas que tienen confirmada esta particularidad y que se encuentran cerca, no tiene mucho respaldo; en el caso de la Casa Hacienda Santa Rosa en el distrito de San Martín de Porres y Chacra Cerro en Comas los indicios son evidentes pues dichas casas haciendas se encuentra sobre un gran montículo de varios metros de alto y de extensión considerable (Arciga, 2016). La Casa Hacienda Punchauca presenta una plataforma o altillo que tiene en su punto más alto solo $2.10 \mathrm{~m}$ de altura y una extensión aproximada de 1125 metros cuadrados. Es considerablemente pequeña como para ocultar grandes vestigios, además habría que agregar que la construcción de casas haciendas sobre un plano sobreelevado es común como menciona Marcela Villa en su trabajo presentado en el $5^{\circ}$ seminario internacional de patrimonio agroindustrial, que indica lo siguiente:

Es interesante apreciar que hasta el siglo XIX tanto en México como en el Perú se buscaba ubicar las casas haciendas en un lugar alto, un promontorio que dominara el paisaje, e inclusive se construía una plataforma, o, en su defecto se ocupaba elsegundo piso del inmueble, estando dedicado el primer piso (planta baja) con oficinas administrativas (Villa, 2016, p. 267).

En base de lo mencionado anteriormente podríamos decir que no necesariamente, porque la Casa Hacienda Punchauca se encuentra construida sobre una plataforma o altillo, debe esta esconder restos de un templo o huaca, ya sea del Periodo Intermedio Tardío (Colli) o del Horizonte Tardío (Inca), ya que es una característica común en el Perú sobreelevar la casa hacienda. Además, en los casos cercanos donde si está confirmado que ocurrió la construcción sobre un sitio prehispánico, es evidente y muy notorio, pues se trata de montículos de grandes dimensiones en cuya cima se construyó. También tendría que tomarse en cuenta que la toponimia hace referencia a la Hacienda Punchauca, la cual debió haber tenido 390 hectáreas tomando en cuenta los límites descritos por Ambrosio Cerdán de Landa Simón Pontero (Cerdán, 1793). De haber existido un templo o huaca esta pudo estar o está en cualquier parte de esta gran área que tuvo la hacienda; por último, no se debe descartar la posibilidad de encontrar mínimas evidencias en la casa hacienda, pues se ubica en una zona cercana a sitios prehispánicos.

Para la época de la Colonia e inicios de la República se cuenta con documentos del Archivo General de la Nación (AGN) con los cuales se puede conocer parte de la historia de Punchauca, estos son los realizados por los escribanos: Pedro Espinoza Alvarado en 1744, Andrés Sandoval 
en 1803, José Escudero de Sicilia en 1820 y Felipe de Orellana en 1851. Además, se cuenta con el «Tratado general sobre las aguas que fertilizan los valles de Lima» de Ambrosio Cerdán de Landa Simón Pontero publicado en 1793, de donde se pueden sacar datos del valle del río Chillón y de la Hacienda Punchauca; y el trabajo de Edgar Quispe Pastrana sobre la casa hacienda.

Después de la conquista del Perú, ya instalado el cabildo de la ciudad de Lima, este le entregó en el año 1543 a Nicolás de Rivera (primer alcalde de la ciudad) 12 fanegadas (la fanega es una unidad de medida tradicional de España, teniendo una equivalencia entre los 0,64 hectáreas, pero en las haciendas limeñas es de 2,5 a 2,7 ha. Usando el factor de conversión las 12 fanegadas serían entre 30 y 32,4 ha) de tierra en la zona de Punchauca, posteriormente en el año de 1556 compró 40 fanegadas (equivalente entre 100 y 108 hectáreas) de tierra a los curacas Francisco Yangue y Cristóbal Yangue, a su fallecimiento en 1563 las tierras pasaron a poder de su viuda Elvira Dávalos, quien en 1594 registró la posesión de 116 fanegadas (entre 290 a 313,2 ha) de tierra en la zona. En 1599 las tierras de Punchauca eran posesión de Francisco de Donoso, quien las había comprado a los hijos y herederos de Elvira Dávalos, pero en 1604 fueron rematadas por deudas y las compró Diego Pérez de ArauzFigueroa, en 1628 muere Arauz y en 1634 sus hijas se repartieron las tierras, Francisca Arauz y Velasco se quedó con la parte sur, a la cual se llamó Huacoy o San Humberto y Catalina de Arieta con la parte norte que mantendría el nombre original (Espinoza, 1744, prot. 304, fs. 622-629). Es interesante mencionar que aunque no existe referencia de la cantidad de tierras que tenía en la zona Diego Pérez de Arauz Figueroa a su muerte, se puede indicar que la adquisición de tierras cercanas siguió, pues se menciona que la zona actual de Huacoy ubicada en el kilometro 22 de la Carretera Túpac Amaru era parte de sus posesiones y que luego su hija Francisca se la quedó. Otro detalle a destacar es que recién en el año 1634 se menciona la existencia en las tierras de Punchauca de casas, ranchos, molinos, trapiches, capilla, caminos, cañaverales y ganado.

Después de la repartición de las tierras de Punchauca en 1634, Catalina de Arieta se casó con Manuel Ríos Salazar en 1639, entregando la hacienda como dote. En 1650 Diego Gonzales Terrones compró las haciendas de Huacoy y Punchauca, y en 1653 vendió la segunda a Anna Ternero de Arrieta (no se sabe si se trata de otra familia, puede tratarse de un error de escritura en los documentos). En 1693 Francisca de Solórzano y Velazco quien fuera hija de Anna Ternero de Arrieta vendió la hacienda y molino al doctor Pedro de la Daga y Vargas, un año después el doctor la vendió al I marqués de Santa María de Pacoyán Martín Joseph Muños Mudarra y Serna, quien la adquirió junto con sus casas, molino, esclavos y ganado. Tiempo después la heredó el II marqués de Santa María de Pacoyán Miguel Joseph Muñoz Mudarra y Roldán, posteriormente fue comprada en remate público por el licenciado Francisco de Paz Presbítero en el año de 1744 (Espinoza, 1744, prot. 304, fs. 630-631). Resalta el hecho de que para los años 1693 y 1694 ya no se hace mención a los trapiches, siendo posible que se dejara de producir derivados del jugo de la caña de azúcar y solo se dedicaran a la harina y ganadería.

Durante la segunda mitad del siglo XVIII la hacienda fue comprada por Lucas Vergara y Pardo, regidor perpetuo de la ciudad de Lima, quien falleció antes del año 1778, dejando en herencia a su hijo Lucas Vergara y Rosas (caballero de la Orden Militar Religiosa de Santiago), el cual la nombró Santiago de Punchauca. En el año 1796 Lucas Vergara y Rosas dio en arriendo por 9 años la hacienda a los hermanos Pablo Guerra y José Guerra, dejando como condición la construcción de una capilla en el sitio que él indicó. Para el año de 1803 el dueño de la hacienda fue Juan Antonio Jimeno quien se la compró a Lucas Vergara y Rosas (Sandoval, 1803, prot. 697, fs. 714-718). Es interesante resaltar que en el documento de Andrés de Sandoval de 1803 es la primera vez que se agrega al nombre de la hacienda el de Santiago, esto debido a que el dueño de esta época Lucas 
Vergara y Rosas, quien perteneció a la Orden de Caballeros de Santiago, decidió cambiarlo. Sobre la extensión que llego a tener la hacienda para finales del siglo XVIII, Ambrosio Cerdán de Landa Simón Pontero en 1793 menciona los límites que tenía entonces. En base a esos datos se puede calcular su extensión en aproximadamente 390 hectáreas; además, se hace referencia que para la época existían dos tomas de agua que abastecían el área agrícola de la hacienda (Cerdán, 1793).

Durante los primeros años del siglo XIX, Juan Antonio Jimeno vendió la hacienda a Jacinto Jimeno. En 1821, los dueños de la Hacienda Santiago de Punchauca eran Jacinto Jimeno y su esposa Mariana Domínguez, quienes recibieron al general don José de San Martín y el virrey José de la Serna. Para 1847, Juan Jimeno y su madre Marina Domínguez viuda de Don Jacinto Jimeno, arriendan la hacienda a José Ausejo. En 1851 la hacienda fue rematada por deudas y lacompró el senador Nicolás de Olivera. (Orellana, 1851, prot. 481, f. 647).

Para los años posteriores a 1851, Edgar Quispe Pastrana en su trabajo nos indica que el dueño de la hacienda fue Pedro Gonzales de Candamo y Aztorga, considerado uno de los hombres más ricos del Perú, quien estuvo casado, desde 1845, con Mercedes Iriarte y Odría, matrimonio del cual nacieron Manuel Candamo Iriarte (presidente del Perú en 1903-1904), Carlos Candamo Iriarte y Mercedes Candamo Iriarte. Al morir Pedro Gonzales de Candamo y Aztorga en 1866, dejó la Hacienda Punchauca en herencia a su hijo Carlos Gonzales de Candamo Iriarte. En 1911, el dueño de la hacienda fue Miguel Echenique y debido a su fallecimiento y por deudas sus herederos la vendieron en 1933 a Luis Nicolini, Ernesto Nicolini y Salvador Giurato, quienes fundaron ese mismo año la Compañía Agrícola Punchauca S.A. (Capsa).Posteriormente, la unión de las haciendas Punchauca, Caudivilla y Huacoy, dio lugar a la formación de la empresa Sindicato de Inversiones Rústicas y Urbanas S.A. (Sirusa). En 1974, los campesinos obtuvieron el beneficio de ser considerados en la Reforma Agraria y 363 socios formaron la Cooperativa Agraria de Productores Caudivilla, Huacoy y Punchauca (Quispe, 2013).

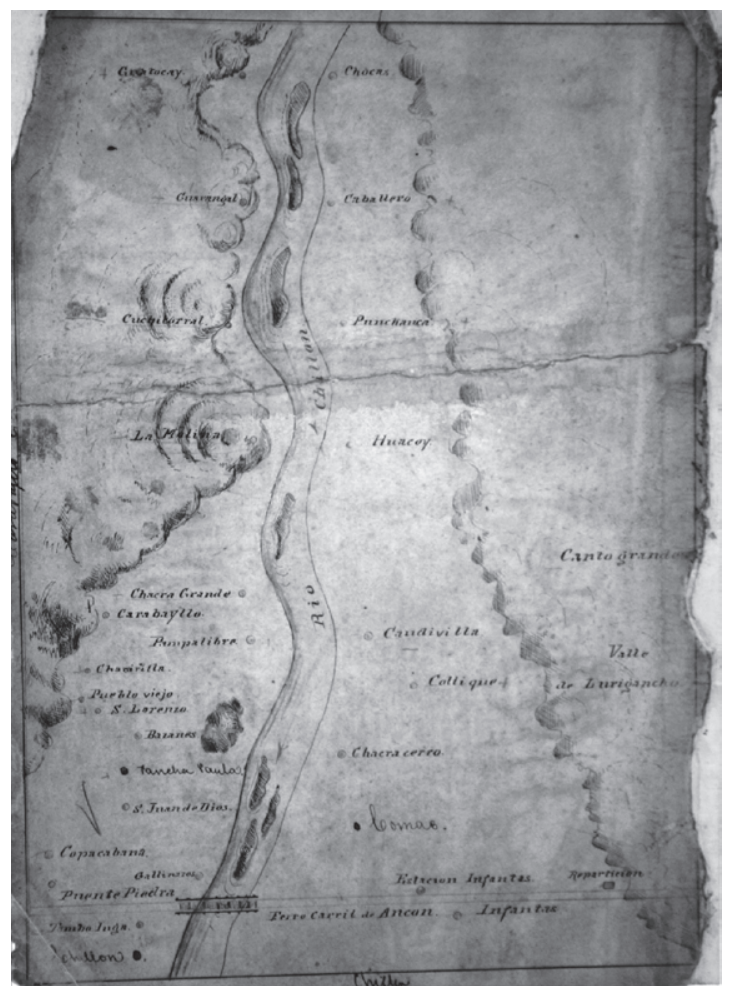

Figura 2. Plano de Carabayllo, Alto y bajo Chillón. En la parte superior se puede apreciar la Hacienda de Santiago de Punchauca: Además, se puede ver los sitios con los cuales limitaba.

Fuente: AGN, Planoteca, Fondo Ministerio del Interior, legajo 34, año 1893. 
La Casa Hacienda Santiago de Punchauca fue declarada monumento de la Nación por

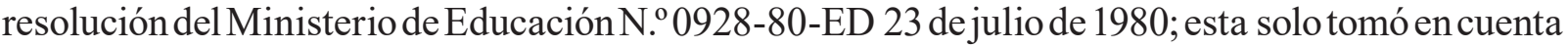
la casa hacienda mas no el complejo agrario y el entorno agrícola. Durante los años posteriores se parceló entre los socios de la cooperativa el área de la antigua hacienda. Posteriormente la Ley N. 24722 de fecha de 11 de septiembre de 1987 creó el Instituto de Investigación Cívico Patriótico e Histórico Toribio Rodríguez de Mendoza en la casa hacienda; hay que aclarar que dicho instituto jamás llegó a funcionar en Punchauca o en otro lugar. Durante toda la última década del siglo XX y la primera del siglo XXI, hubo una despreocupación por parte del gobierno central y local de mantener el sitio; fue así como gran parte de los muros de la Casa Hacienda Punchauca colapsaron, la infraestructura agrícola que se encontraba a su alrededor fue demolida y reemplazada por construcciones modernas. En los últimos años de la primera década del siglo XXI y con mayor fuerza en la siguiente se comenzó con un proceso de lotización el cual alteró para siempre el entorno agrícola que tuvo la zona desde la época Prehispánica. El 31 de enero de2012 se firmó un convenio de cooperación interinstitucional entre la Municipalidad distrital de Carabayllo y el Ministerio de Cultura del Perú para salvaguardar la Casa Hacienda Punchauca. En el año 2013 la bancada del Congreso del Acción Popular y Frente Amplio presentaron un proyecto de Ley que declara de preferente interés nacional la restauración, conservación, investigación de la Casa Hacienda Santiago de Punchauca del distrito de Carabayllo, el mismo que hasta la fecha no ha sido aprobado. Fue a raíz de una campaña realizada para la restauración de la Casa Hacienda Punchauca y del proyecto de ley, que el Ministerio de Cultura realizó trabajos de conservación, delimitación física y legal a partir del año 2013.

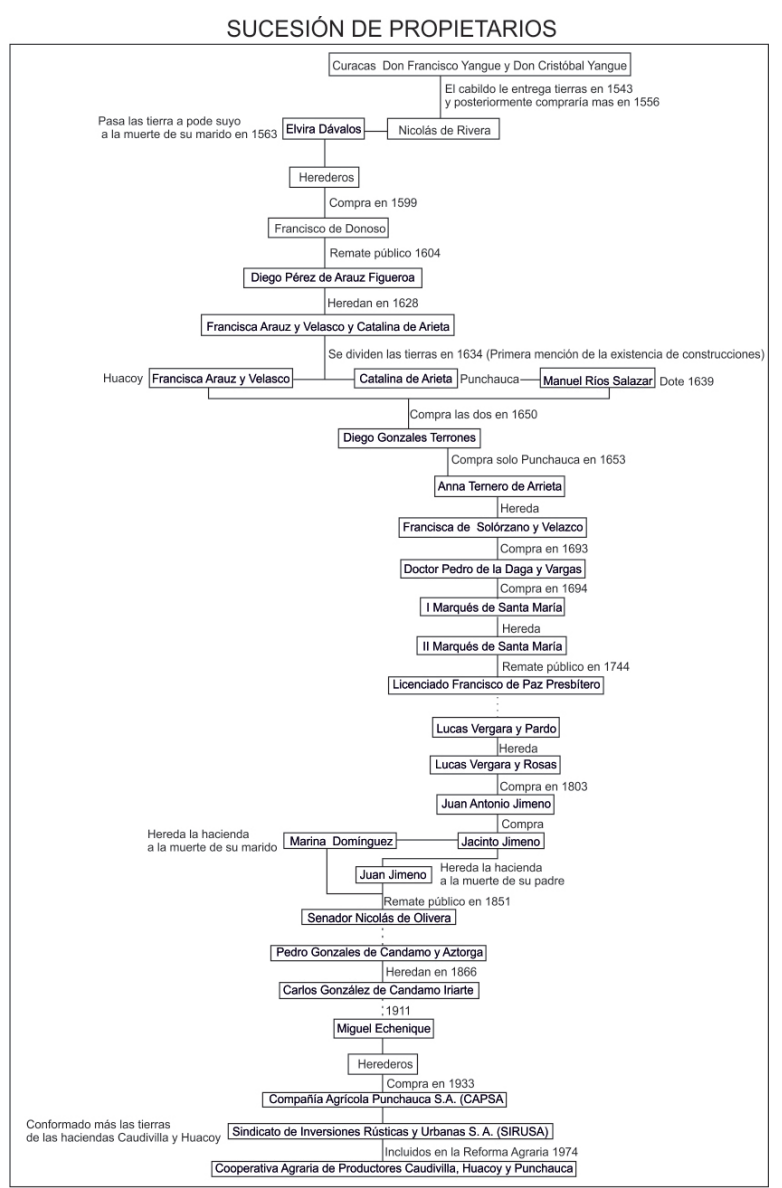

Figura 3. Cuadro de secesión de propietarios de la Hacienda Santiago de Punchauca

Fuente: Rolando Arciga, 2017 


\section{Arquitectura}

De la infraestructura que tenía la Hacienda Punchauca, gran parte se ha perdido en las últimas décadas, dando paso a construcciones modernas, solo quedando en la actualidad algunas casas de trabajadores, almacenes y la casa hacienda. Hoy en día un proceso de lotización pone en riesgo el resto de estructuras del complejo agrícola que no se encuentran declarados como patrimonio cultural de la nación, pues la delimitación del área monumental solo contempla la casa hacienda (además de un almacén y corral que se encuentran adosados).

La importancia de la arquitectura de la Casa Hacienda Punchauca radica en ser un ejemplo rural de tipo casa hacienda de la época de la colonia (del cual quedan pocos en el valle del Chillón), solo recibiendo modificaciones significativas en el siglo XIX, como la realizada en la fachada principal. Sobre la descripción de la arquitectura de la casa hacienda podemos decir que se encuentra construida sobre una plataforma de 2,10 m de altura. La Casa Hacienda Punchauca obedece al sistema constructivo de crujías, sus muros están construidos con adobes siendo usado el sistema de ordenamiento de aparejos inglés, su grosor es de $70 \mathrm{~cm}$ en promedio; existen también otros que tienen $40 \mathrm{~cm}$ y que fueron hechos a tizón. Los adobes con los cuales se construyó la casa hacienda fueron hechos en molde de $12 \mathrm{~cm}$ de alto, $20 \mathrm{~cm}$ de grosor y $35 \mathrm{~cm}$ de largo. La altura de los muros en la parte delantera es de 3,90 $\mathrm{m}$ y de 3,20 $\mathrm{m}$ en la parte posterior. El techo de sus habitaciones era entablado de madera y la cobertura de la capilla fue de bóveda de medio cañón. Tenía piso de baldosa hidráulica y de ladrillo. Presentó un total de 19 recintos, siendo ellos: pasadizo adintelado, capilla, sacristía, cuarto del doctor, sala, terraza, baño, cuarto de tránsito, dormitorio, patio, tópico, comedor, pasadizo, cuarto del harinero (presentaba dos muros internos), cocina, enfermería de hombres (se levantó una separación), de mujeres, corral y cepo. (Escudero, 1820, prot. 219, fs. 36-38) (Orellana, 1851, prot. 481, fs. 678-679).

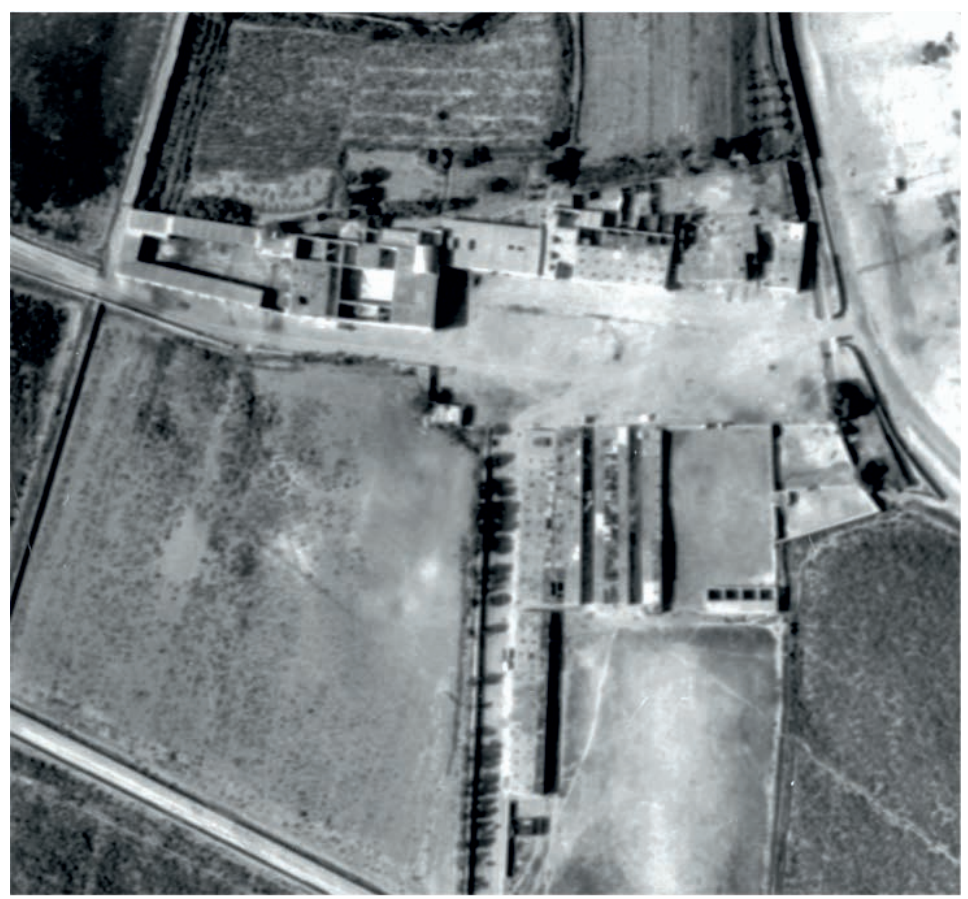

Figura 4. Fotografía aérea del Complejo de la Hacienda Santiago de Punchauca.

Fuente: Servicio Aerofotográfico Nacional, 1945. Se puede ver la Casa Hacienda, caballerizas, corrales, almacenes, depósitos y casas de trabajadores. 
La secuencia constructiva de la Casa Hacienda Punchauca puede ser descrita en base a los documentos antiguos y con el apoyo del principio de la identidad tipológica usado en el análisis estratigráfico de construcciones históricas, Luis Caballero Zoreda en su trabajo «Método para el análisis estratigráfico de construcciones históricas o lectura de paramentos», menciona que los elementos que presentan el mismo material, el tipo de aparejo y técnica son de la misma época; es así como estos sirven para fechar, tanto a la construcción como a partes de esta (Caballero, 1995). En el caso de la casa hacienda esta presenta casi todos los muros construidos con adobe (salvo algunas refacciones hechas con ladrillo), del mismo tamaño, pero hay una diferencia en los muros en alturas, ancho y ordenamiento de aparejos; es en base a estas diferencias y además usando los documentos, que se puede ordenar la evolución del monumento. La planta original de la casa hacienda era en forma de «U», ubicándose al centro un patio interior en forma rectangular, alrededor había habitaciones que tenían 3,90 m de altura y $70 \mathrm{~cm}$ de ancho; este momento constructivo debe corresponder a fechas desde la primera mitad del siglo XVIII para atrás, no pudiendo determinar la fecha exacta. Para la segunda mitad del siglo XVIII la casa hacienda presentaba una planta de forma de «O», debido a que en la parte posterior se construyeron cuartos, los cuales tenían 3,20 m de altura; el color con el cual estaba pintada la casa era el añil. Entre los años 1796 y 1803 se agregó la capilla-sacristía y se construyó un baño; estos alteraron la planta original en forma de «O» que presentaba la casa hacienda, además, se le dio a la fachada un estilo Neoclásico. (Sandoval, 1803, prot. 697, f. 716) (Escudero, 1820, prot. 219, fs. 33-38). Posteriormente en el año 1851 se prolongó el pasadizo reduciendo el área del patio y además se reemplazaron los muros colapsados por nuevos con un grosor de $40 \mathrm{~cm}$ de ancho; el color que presentaba la casa era el ocre.

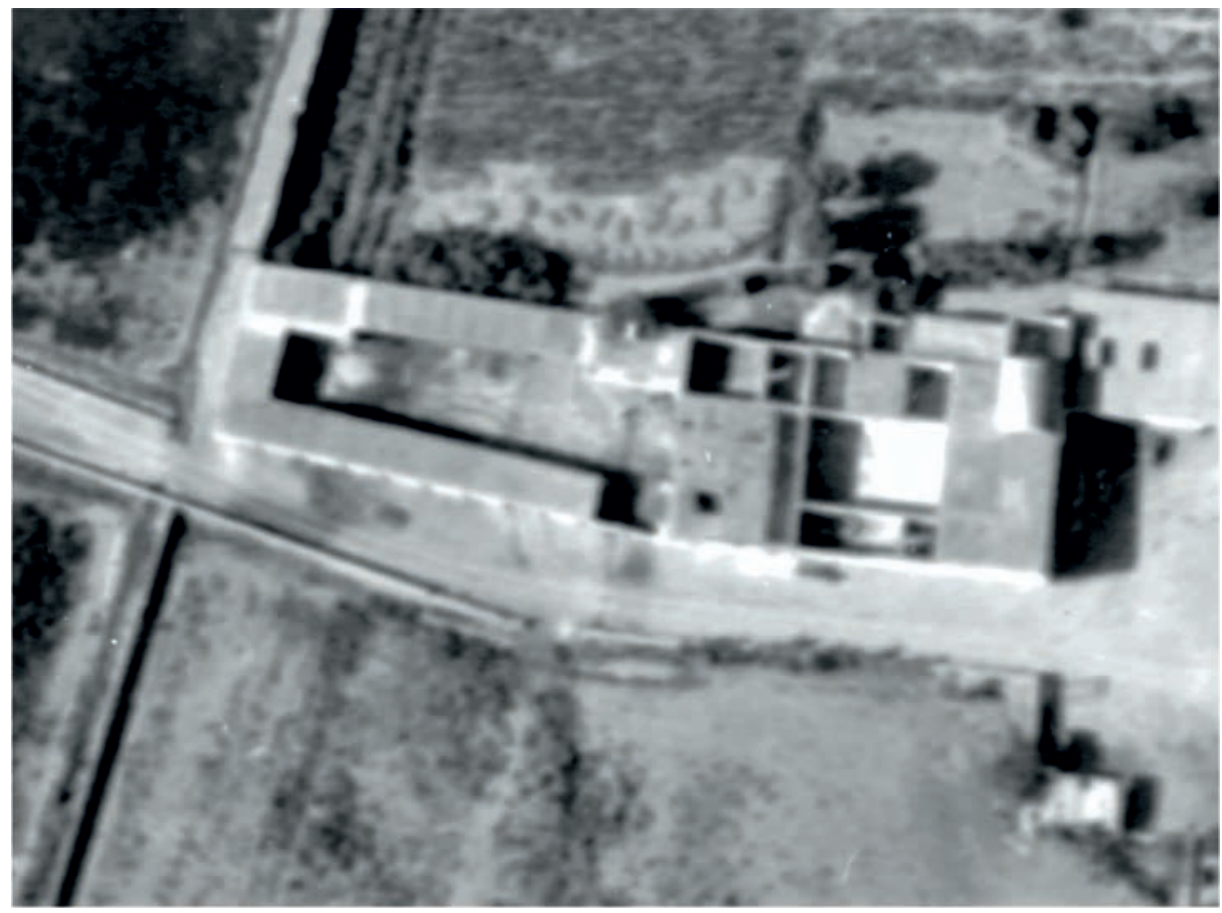

Figura 5. Fotografía aérea del Casa Hacienda Santiago de Punchauca

Fuente: Servicio Aerofotográfico Nacional, 1945. Se puede ver la Casa Hacienda y adosada a ella el corral y la caballeriza.

En el caso de la Casa Hacienda Punchauca se aprecian cuatro fachadas: la principal, lateral derecha, izquierda y posterior. La fachada principal es de estilo Neoclásico, en la parte inferior se aprecia la plataforma o altillo y adosada a esta hay una escalera de doble tramo; en la parte 
superior se aprecian cuatro columnas y dos pilastras de orden toscano que sostienen un techo entablado; al lado izquierdo se encuentra la capilla, la cual presentaba una bóveda a medio cañón y un vano. En la fachada lateral derecha había siete vanos (3 de estos no se distinguen en la actualidad) y un ingreso desde una escalera de doble tramo. En la fachada lateral izquierda se aprecian la sacristía con su vano, la terraza que tenía una escalera que caía en la huerta, el baño, el cuarto del harinero con dos vanos (los que debido al colapso del muro desaparecieron), también a la altura del baño se podía apreciar una ventana teatina que brindaba luz al dormitorio de la casa hacienda (no existe hoy en día). La fachada posterior de la casa hacienda presenta cuatro contrafuertes y tres vanos (el muro donde estaban se derrumbó), que brindaban luz a la cocina, enfermería de mujeres y hombres. Además, presenta un corral adosado al lado izquierdo de la casa hacienda (Escudero, 1820, prot. 219, fs. 36-38; Orellana, 1851, prot. 481, fs. 678-679).

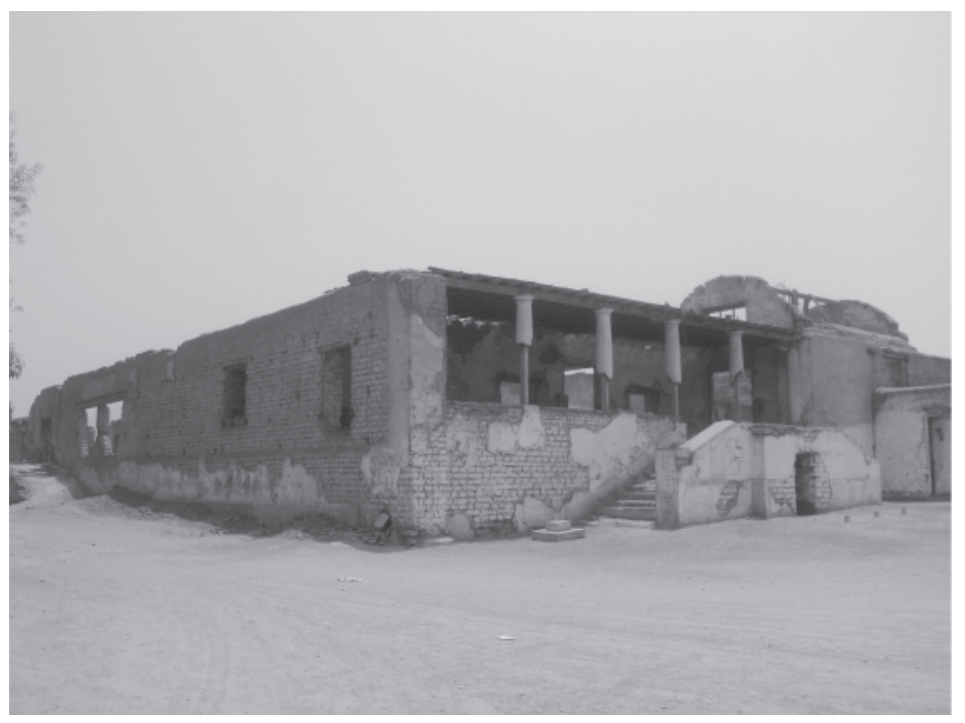

Figura 6. Foto de la Casa Hacienda Santiago de Punchauca.

Fuente: Rolando Arciga, 2012

La descripción de los espacios internos que tenía y tiene es la siguiente: subiendo por las escaleras, por donde se llega al pasadizo adintelado, se aprecian columnas y pilastras de orden toscano que tienen su alma de madera y están revestidas con quincha, estas sostienen un techo entablado; desde este espacio se tienen accesos a la sala, el cuarto del doctor y la capilla; tenía además un vano que miraba al camino, que está a la derecha de la casa hacienda y dos a la sala (Escudero, 1820, prot. 219, f. 36; Orellana, 1851, prot. 481, f. 678). Debajo de la escalera se encuentra un pequeño recinto que tenía como función ser un cuarto de cepo o de castigo, este tiene un solo acceso que da afuera de la casa hacienda (Escudero, 1820, prot 219, f. 36; Orellana, 1851, prot 481, f. 679). La capilla presentaba como cobertura una bóveda a medio cañón y en su interior tenía un retablo de estilo neoclásico hecho en madera, construido en los primeros años del siglo XIX. Este estaba conformado por cuatro columnas en su cuerpo, una hornacina en el centro y en su ático una imagen del apóstol Santiago a caballo. El ambiente tiene accesos al pasadizo adintelado y sala; además tenía otro que lo comunicaba con la sacristía, pero este fue sellado antes del año 1820; y al lado izquierdo de donde estaba el retablo, un vano (Sandoval, 1803, prot. 697, f. 716) (Escudero, 1820, prot. 219, fs. 33-36; Orellana, 1851, prot. 481, fs. 667-678). La sacristía tenía un acceso que la intercomunicaba con la capilla; este fue sellado cuando se cambió de función, convirtiéndose para antes de 1820 en cuarto de estudio. Actualmente solo presenta uno a la terraza; además tiene un vano que mira hacia la huerta y una hornacina (Escudero, 1820, prot. 219, f. 37; Orellana, 1851, prot. 481, f. 679). Desde la sala 
se tienen accesos a la capilla, pasadizo adintelado, terraza, cuarto de tránsito, patio y cuarto del doctor. Presenta un techo entablado; tiene dos vanos con vista al pasadizo adintelado, patio y terraza. La sala no presenta una forma rectangular o cuadrangular, que correspondería con el sistema constructivo de crujías. La razón de esto es que al construir la capilla-sacristía, durante los años 1796 y 1803, se alteró la forma original; anteriormente la sala tenía un cuarto a la derecha y a su izquierda, ambos de igual ancho que esta, pero menores en su largo, el de su izquierda fue afectado por la construcción de la capilla-sacristía, siendo su área reducida; lo que quedo de este fue adicionado a la sala (Escudero, 1820, prot. 219, f. 36; Orellana, 1851, prot. 481, f. 678). El cuarto del doctor presenta en su piso 3 tipos diferentes de baldosas hidráulicas; tiene accesos al pasadizo adintelado, sala y tópico; además, tiene un vano que mira hacia el camino que está a la derecha de la casa hacienda (Escudero, 1820, prot. 219, f. 38) (Orellana, 1851, prot. 481, f. 678). El cuarto de tránsito presenta accesos al patio y a la sala, tenía otro a la terraza pero este fue sellado en años recientes; antiguamente existieron dos accesos más que comunicaban con el dormitorio. La pérdida del enlucido ha dejado expuesto los accesos, estos debieron ser sellados después de 1851 (Escudero, 1820, prot. 219, f. 36; Orellana, 1851, prot. 481, f. 678). El dormitorio presenta acceso al patio; tenía otro al baño pero este fue sellado en años recientes. Además, presentaba una ventana teatina en su techo; anteriormente tenía dos accesos que lo comunicaban con el cuarto de tránsito, pero como ya se mencionó estos fueron sellados después de 1851 (Escudero, 1820, prot. 219, f. 37; Orellana, 1851, prot. 481, f. 678). La terraza tiene accesos a la sacristía y al baño; los tenía también a la sala y cuarto de transitopero estos fueron sellados en años recientes. Presentaba cuatro columnas de madera, tenía un techo entablado y una escalera con tres peldaños que daban hacia la huerta de la casa; al lado de esta se encuentra una acequia que hasta el día de hoy se utiliza para irrigar los campos agrícolas (Escudero, 1820, prot. 219, f. 37; Orellana, 1851, prot. 481, f. 678). El baño tiene acceso a la terraza; lo tenía también al dormitorio pero este fue sellado en años recientes. Actualmente de este espacio no queda ningún muro en pie (Escudero, 1820, prot. 219, f. 37; Orellana, 1851, prot. 481, f. 678). El patio tenía accesos a la sala, tópico, cuarto del harinero, dormitorio, cuarto de tránsito, pasadizo y dos para el comedor; este hasta hace algunos años presentaba acumulación de material colapsado, proveniente de los muros cercanos de los cuartos; su forma original rectangular fue de mayor extensión.
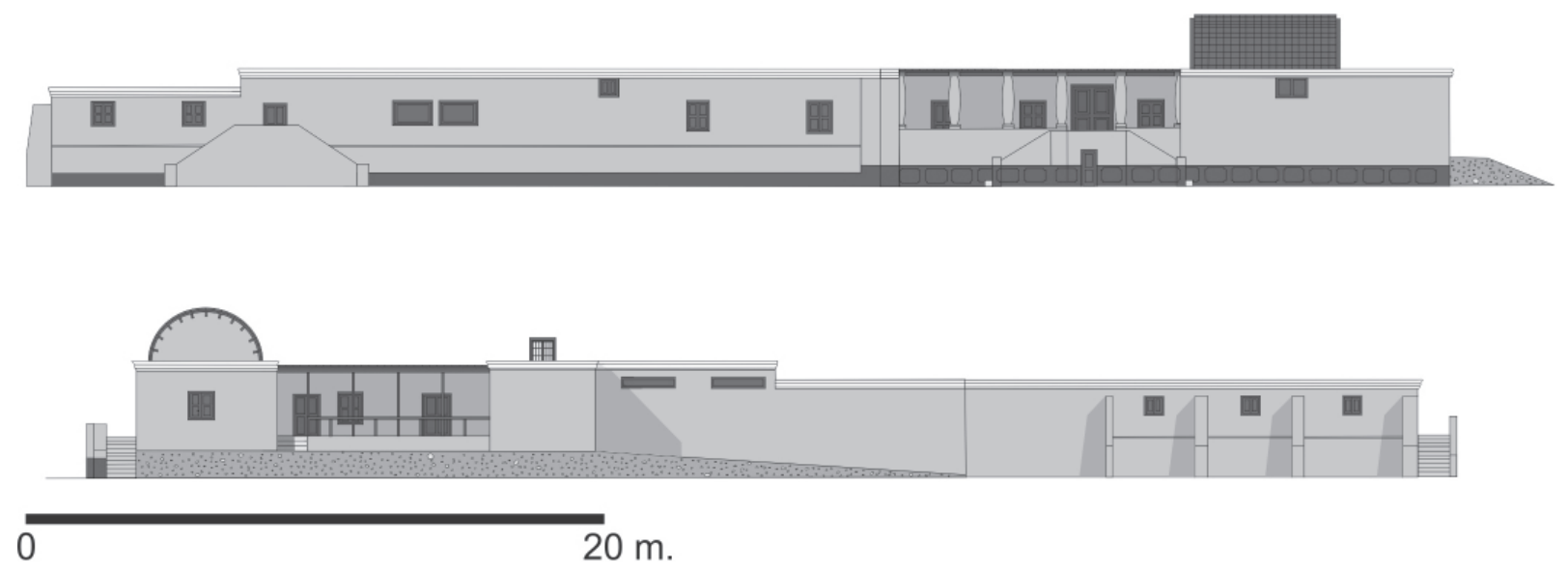

Figura 7. Vista de la recreación de las fachadas de la Casa Hacienda Santiago de Punchauca.

Fuente: Rolando Arciga, 2017. En la parte superior se aprecia la lateral derecha y principal; en la parte inferior se encuentra la lateral izquierda y posterior 

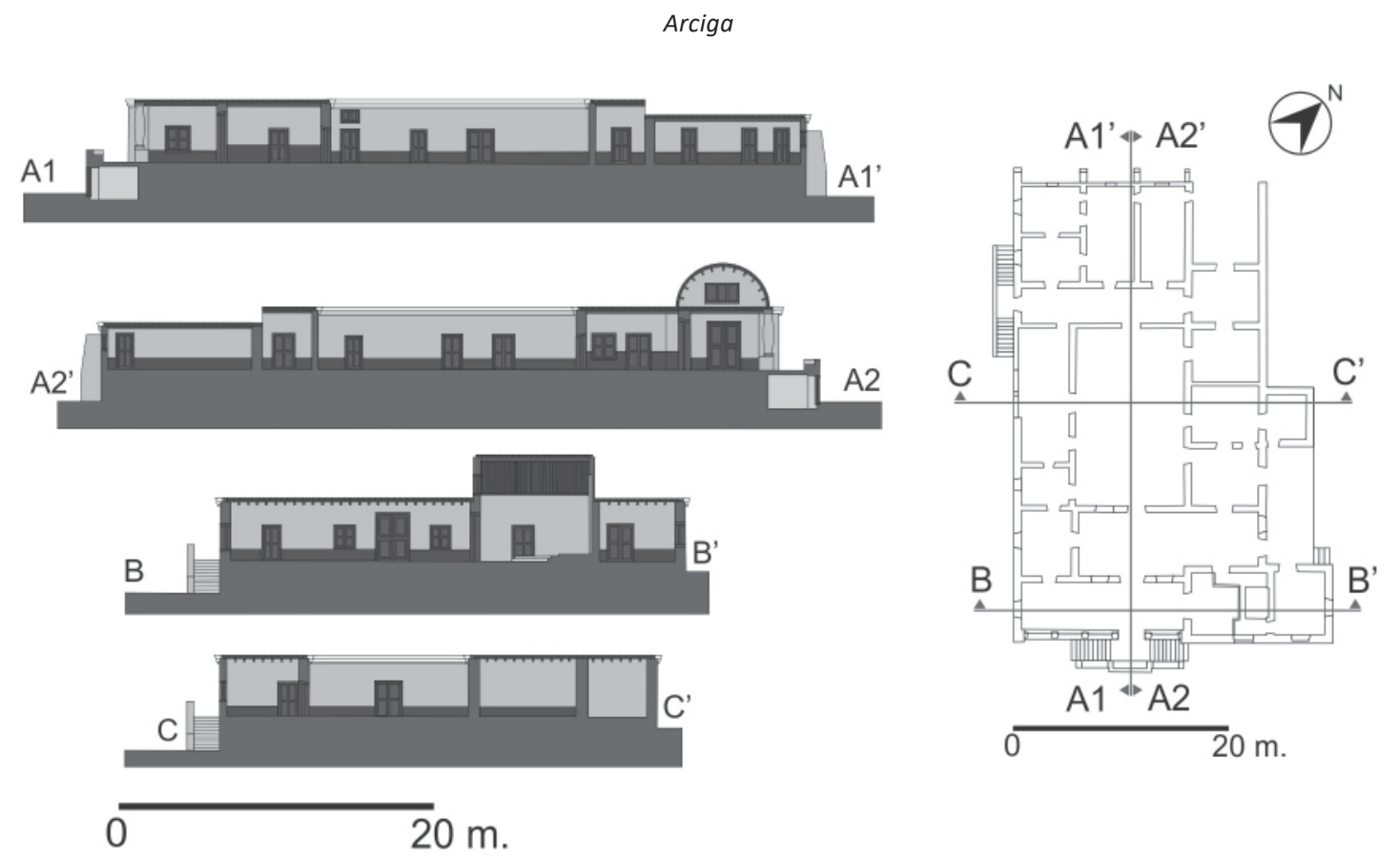

Figura 8. Cortes de la Casa Hacienda Santiago de Punchauca.

Fuente: Rolando Arciga, 2017

Posteriormente al año 1851 se levantó un muro de un grosor de $40 \mathrm{~cm}$ que redujo su área (Escudero, 1820, prot. 219, f. 38; Orellana, 1851, prot. 481, f. 679). El tópico tiene accesos al cuarto del doctor, patio y comedor y presenta en su piso un tipo de baldosa hidráulica que difiere de las del cuarto del doctor; además tenía un vano que daba al camino que está a la derecha de la casa hacienda (Ibidem). El comedor tenía dos accesos al patio, uno al tópico y otro al pasadizo. Presenta dos vanos que miran hacia fuera de la casa hacienda por donde está un camino. El muro donde están tiene $40 \mathrm{~cm}$ de grosor; había otro que servía como separación con el pasadizo que era también de $40 \mathrm{~cm}$ de ancho (Ibidem). En el caso del pasadizo, posteriormente al año 1851, se construiría un muro de grosor de $40 \mathrm{~cm}$ que aumentaría su extensión a costa del área del patio; ya con esa configuración tenía accesos al patio, al comedor, enfermería de hombres, mujeres, cocina, cuarto del harinero y por ultimo uno que daba a la escalera del lado derecho (Ibidem). El cuarto del harinero tenía accesos al patio, pasadizo, cocina y al corral; también tenía dos vanos que miraban para fuera de la casa hacienda; presentaba dos muros que lo dividiría en tres ambientes; en este espacio había un piso de ladrillo (Escudero, 1820, prot. 219, f. 37; Orellana, 1851, prot. 481, f. 679). La cocina tenía accesos a la enfermería de mujeres, cuarto del harinero y pasadizo; también tenía un vano que miraba a la caballeriza (Escudero, 1820, prot. 219, f. 38; Orellana, 1851, prot. 481, f. 679). La enfermería de mujeres tenía acceso al pasadizo y presenta otros tres accesos que la comunicaban con el de hombres. También tenía uno con la cocina pero este fue sellado en épocas recientes; además, presentaba un vano que miraba a la caballeriza. (Ibidem). La enfermería de hombres tenía acceso al pasadizo y presentaba otros tres accesos que la comunicaban con la de mujeres. Además, había un vano que daba a la caballeriza y otros 2 que miraban a un camino que se encuentra al lado derecho de la casa hacienda. Posteriormente a 1851 se levantó un muro de $40 \mathrm{~cm}$. de grosor que dividía en dos el ambiente (Ibidem). 


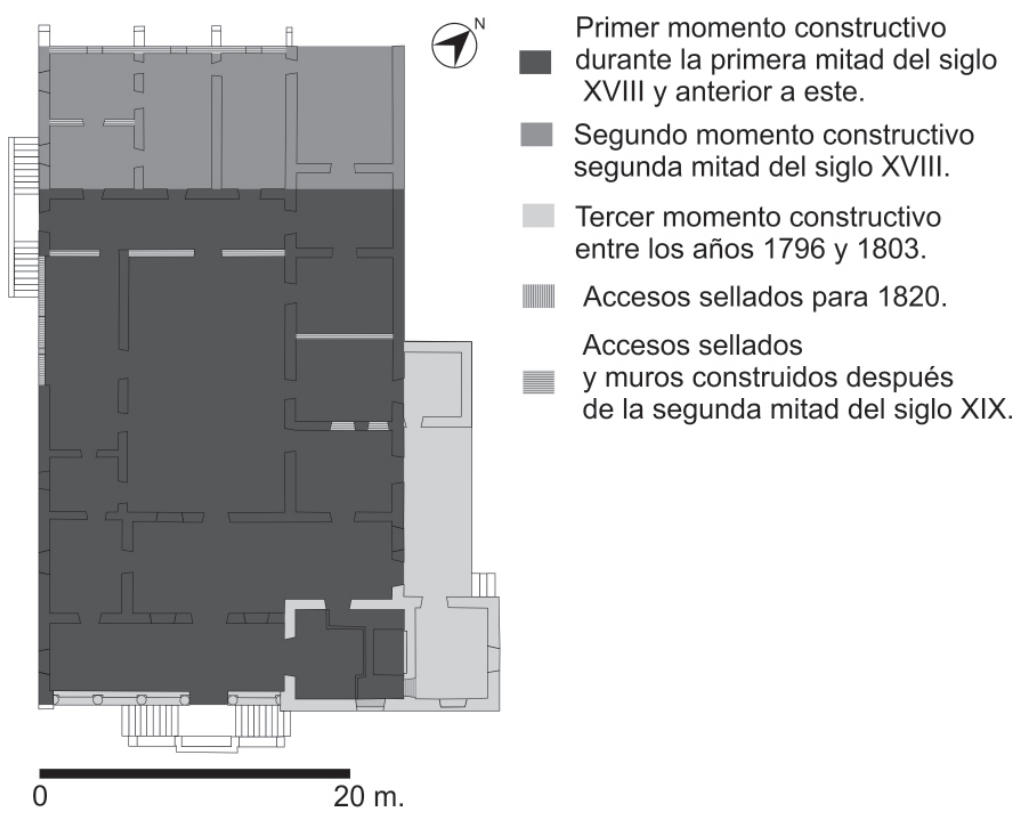

Figura 9. Secuencia constructiva de la Casa Hacienda Santiago de Punchauca.

Fuente: Rolando Arciga, año 2017

A partir de fines del siglo XX se aceleró el proceso de deterioro en la arquitectura de la Casa Hacienda Punchauca, que siguió durante la primera década del siglo XXI. Fue así como esta terminó perdiendo el enlucido en los muros, se desplomó el techo entablado de los recintos, desaparecieron la mayoría de los espacios y su piso original. Los muros de los recintos que se encontraban cerca al patio se desplomaron y los que aún quedan en la parte posterior presentan erosión en sus bases. A partir del año 2013, el Ministerio de Cultura comenzó con los trabajos de conservación, con el fin de evitar más daños en la casa hacienda. A la fecha no se han comenzado los trabajos de restauración propiamente dichos que buscarían devolverle su aspecto original.

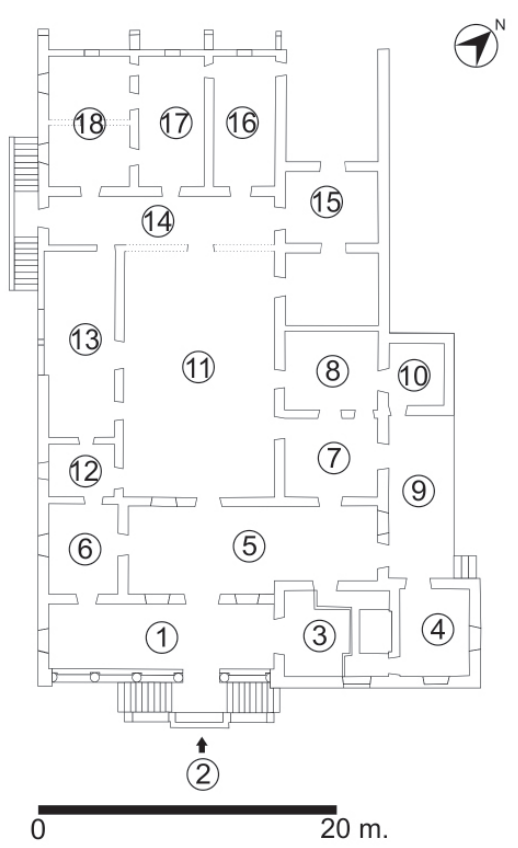

(1) Pasadizo adintelado

(2) Cepo

(3) Capilla

(4) Sacristía

(5) Sala

(6) Cuarto del Doctor

(7) Cuarto del Transito

(8) Dormitorio

(9) Terraza

(10) Baño

(11) Patio

(12) Tópico

(13) Comedor

(14) Pasadizo

(15) Cuarto del Harinero

(16) Cocina

(17) Enfermeria de Mujeres

(18) Enfermería de Hombres

Muros posteriores que dividieron los espacios

Figura 10. Plano de función de los espacios de la Casa Hacienda Santiago de Punchauca.

Fuente: Rolando Arciga, año 2017 


\section{Puesta en valor}

La puesta en valor, como explica José Hayakawa en su libro «Restauro UNI», es una operación técnica y sistemática cuyo fin es darle un nuevo uso a un bien conforme a su naturaleza, destacando y exaltando sus características y valores (Hayakawa, 2012). La puesta en valor en la Casa Hacienda Punchauca tendría que tener las siguientes etapas: la conservación, restauración y la selección de un modelo de gestión adecuado para la interpretación del sitio. Debemos tener en cuenta que la restauración no es el fin, al momento de intervenir un monumento, es una parte de un proceso mayor que busca darle un nuevo uso al sitio y beneficiar a la sociedad.

La conservación como menciona Ximena Vela Cisneros en su «Glosario de Arquitectura», en un sentido simple sería el: "Conjunto de técnicas orientadas a salvaguardar la integridad de un edificio; realiza actuaciones preventivas en el patrimonio arquitectónico a fin de evitar su deterioro» (Vela, 2010, p. 28). Las labores realizadas en la Casa Hacienda Punchauca a partir del año 2013 por parte del Ministerio de Cultura estuvieron enmarcadas en trabajos de conservación, pues se buscó parar el deterioro de su estructura. Ahora la conservación, según la clasificación que hace Salvador Muñoz en su libro Teoría contemporánea de la restauración, puede ser dividida en dos, la primera es la conservación ambiental, a la cual define así: "conservación ambiental, que es la actividad que consiste en adecuar las condiciones ambientales en que se halla un bien para que este se mantenga en un estado presente» (Muñoz, 2003, p. 23). El segundo tipo según la clasificación de Salvador Muñoz es la conservación directa, la cual indica que es:

La actividad que consiste en preparar un bien determinado para que experimente la menor cantidad posible de alteraciones interviniendo directamente sobre él, e incluso alterando o mejorando sus características no perceptibles, se entiende, para un espectador medio en las condiciones habituales de observación de ese bien. La conservación directa también puede alterar rasgos perceptibles, pero solo por imperativos técnicos (Muñoz, 2003, pp. 23-24).

Las acciones hasta el momento efectuadas en el monumento son de conservación directa, pues no se han mejorado las condiciones ambientales, incluso se puede describir la situación de las condiciones de su alrededor como agresivas con respecto al bien. El proceso de lotización está encerrando cada vez más las estructuras que aún quedan, a la vez que elimina el entorno agrícola que se ha mantenido desde la época prehispánica, haciendo que se descontextualicen dichas estructuras. Además, para concluir sobre el tema de la conservación, una vez terminada la puesta en valor en el monumento se tendrá que realizar monitoreo en los meses y años posteriores, con el fin de ver cómo reacciona el monumento después de la intervención y prevenir en el futuro daños en su arquitectura.

Salvador Muñoz define así la restauración: «Restauración, es la actividad que aspira a devolver a un estado anterior los rasgos perceptibles de un bien determinado -perceptibles, se entiende, para un espectador medio en condiciones normales de observación-» (Muñoz, 2003, p. 24). Cuando hablamos de una restauración en la Casa Hacienda Punchauca debemos tener en cuenta que gran parte de su estructura se ha perdido. Esto implicaría la toma de decisión de cuál sería la magnitud de la restauración, si se restaurara todo o solo una parte. Una reconstrucción total de una estructura de la cual gran parte ya no existe se puede tomar como un falso histórico. Otros puntos sobre la restauración los podemos ver en el trabajo de Giovanni Carbonara sobre las «Tendencias actuales de la restauración en Italia», quien hace una relación de los principios de la restauración científica, estos son la distinguibilidad, reversibilidad, autenticidad, mínima intervención y compatibilidad (Carbonara, 1998). La distinguibilidad de los materiales actuales 
en las restauraciones se refiere a que los agregados modernos puedan ser fácilmente reconocidos. La reversibilidad es un principio que nos indica que los agregados modernos podrían ser retirados de las partes originales si fuera necesario. La autenticidad menciona que cualquier elemento agregado en la intervención debe ser fácilmente distinguible sin que esto sea violento o estridente. La mínima intervención trata de limitarse a intervenir cuando sea totalmente necesario, para no alterar demasiado el monumento. Y por último la compatibilidad hace referencia al uso de materiales que no alteren o dañen o provoquen alguna reacción adversa al monumento, siendo lo ideal el uso de elementos hechos con los mismos materiales que los originales.

Sobre el uso que se le debe dar al monumento, Antoni Gonzáles Moreno-Navarro en su trabajo sobre «La restauración objetiva», menciona:

La restauración objetiva, por definición. Constituye un criterio esencial, garantizar el uso del objeto, el monumento, un uso sensato, compatible con la permanencia de sus valores esenciales (Documentales, arquitectónicos y significativos). En primer lugar, siempre que sea posible y éticamente conveniente, el uso primigenio, en cuanto este forme parte esencial del valor documental. Y si no fuera posible, el más adecuado para satisfacer el objetivo genérico de la restauración sin perjudicar el monumento (Gonzáles, 2000, p. 115).

Para el caso de la Casa Hacienda Punchauca es evidente que no se puede dar el uso primigenio, además mediante Ley N. ${ }^{\circ} 24722$ de fecha de 11 de septiembre de 1987 se indica que se usaría como sede del «Instituto de Investigación Cívico Patriótico e Histórico Toribio Rodríguez de Mendoza» y hasta el momento no se ha derogado o modificado dicha ley. Ahora se tendría que tener en cuenta la factibilidad del funcionamiento de la institución en la zona, siendo esta alejada de la ciudad de Lima, en un área que está en proceso de expansión urbana y que el monumento no se encuentra en el mismo estado que en el año 1987 cuando presentaba una menor cantidad de daños. Referente al nuevo uso que debería darse, este tendría que decidirse a través de un análisis de la realidad actual de la zona, su proyección en el futuro y el nivel de restauración al que se podría llegar. Por último, recalcar que el uso que se le dé al monumento, deberá ser aquel que cause menos modificaciones.

Sobre el modelo de gestión, Claudio Cabezas Capetillo nos explica en su «Guía Metodológica para la elaboración de modelos de gestión del patrimonio cultural Inmueble», lo siguiente: «modelo de gestión es la descripción del proceso administrativo que existe o se pondrá en marcha dentro de una institución con el fin de organizar los recursos que contribuirán a la sostenibilidad del patrimonio cultural inmueble» (Cabezas, 2010, p. 3). El modelo de gestión no solo indica qué tipo de administración tendrá, si será pública, privada o mixta; además, tiene que ver con el uso que se dará al bien, como un museo, centro cultural, casa de la cultura, entre otros. También puede hacer referencia al papel de la población local. El modelo de gestión debe ser sostenible no solo desde el punto de vista de la duración del nuevo uso asignado en el monumento, sino también deberá generar una rentabilidad, de cuyo resultado una parte sea usada en el mantenimiento y conservación. Por último en el modelo de gestión se deberá incluir a la población local. Es indispensable que en la intervención se la sensibilice con el monumento, ya que en muchos casos los habitantes son el principal agente de deterioro de la Casa Hacienda Punchauca. Es recomendable la realización de talleres con los niños y charlas con las personas adultas de la comunidad, la meta fundamental del trabajo es que ellos sean los primeros en preservar y cuidar el monumento.

Una posible propuesta para gestionar el patrimonio cultural de Punchauca, teniendo en cuenta la realidad actual de la zona, es la creación de un centro de interpretación en la casa hacienda. La 
interpretación del patrimonio según Freeman Tilden quien es el primero que define el concepto, es: "una actividad educativa que pretende revelar significados e interrelaciones a través del uso de objetos originales, por un contacto directo con el recurso o por medios ilustrativos, no limitándose a dar una mera información de los hechos» (Tilden, 2006, p. 35). Sobre la definición de centro de interpretación, Emilio de Domingo Angulo en su trabajo sobre «Los centros de interpretación históricos, artísticos y Arqueológicos en la Provincia de Burgos», así los define:

Los centros de Interpretación son equipamientos culturales, muy ligados a la museología, incluso algunos los denominan paramuseos cuya función principal es la de comunicar y hacer comprensible un bien cultural a través de un lenguaje sencillo y ameno, utilizando muchas veces las nuevas tecnologías y técnicas museográficas, buscando acercar al visitante, de forma lúdica, el significado del legado patrimonial de los bienes a interpretar. Tienen la particularidad de que no hace falta que el bien se encuentre allí, ya que, además, no tienen por qué ser bienes tangibles, sino también intangibles y tampoco es necesaria la utilización de materiales originales para su exposición. Hoy en día se utilizan mucho en estos equipamientos copias, reproducciones e incluso nuevas técnicas en que el carácter virtual sustituye a la realidad, como puede ser a través de pantallas o aplicando técnicas de realidad aumentada (De Domingo, 2014, p. 27).

De la cita anterior podemos extraer que el centro de interpretación a diferencia de un museo no necesariamente debe contar con objetos históricos, puede enseñar a través de otros recursos como son las reproducciones, paneles informativos, etc.; esto lo libra de los mantenimientos en conservación que tendría al exhibir objetos de valor histórico. Su objetivo es dar una interpretación fácil y sencilla que pueda ser entendible por todo el público a diferencia de los museos, cuya información, en la gran mayoría de casos, es académica. La elección del modelo de centro de Interpretación para realizarse en Punchauca está justificada por el hecho de que no se cuenta con una gran área, pues solo se ha declarado como patrimonio la casa hacienda. De haber sido preservado el resto y mantenida la actividad agrícola, se habrían podido aplicar el turismo comunitario, el ecomuseo, entre otras opciones. Un problema para instalar un museo es que no se cuenta con piezas propias para ser exhibidas en el sitio. De conseguir otras, ajenas al monumento, el mantenimiento de estas sería un costo extra y se tendría que asumir el tema de seguridad en una zona al extremo de la ciudad donde no hay mucha vigilancia. Otro tema es la población local; el centro de interpretación seria el modelo más adecuado para lograr un nexo con la comunidad pues su forma de brindar la información es fácil y sencilla. Deberá además, por tal motivo, realizar una serie de actividades con el fin de acercar a los habitantes al monumento; la administración y el financiamiento deberán recaer en el gobierno, pero con la meta de llegar a ser autosuficiente económicamente, gracias a fondos obtenidos a través de diferentes actividades que puedan ser ofrecidas al público.

\section{Experiencias de intervenciones en haciendas para uso como espacios culturales (museos y centros de interpretaciones)}

En lo que se refiere a experiencias de intervención en haciendas habría que destacar el caso mexicano, debido al gran número de intervenciones, años de experiencia en la ejecución de proyectos, casos ampliamente estudiados y diferentes usos que se han dado. En el caso de los usos, Laura Gemma Flores García los clasifica en: Mercado inmobiliario, en el cual no se involucra a los habitantes de los alrededores, no hay una mejora de la calidad de vida de la población. Tiene un énfasis en el aspecto económico, que se traduce en beneficio para los 
propietarios; se cumplen en parte las normas de conservación (pero solo aquellas relativas a los elementos que están a la vista, como las fachadas). Hotelería y turismo, en donde se involucra hasta cierto punto a la población aledaña. Al haber una incorporación de la comunidad en el campo laboral, hay una leve mejora en la calidad de vida. Se resalta también lo económico, la arquitectura es sometida a una serie de intervenciones para restaurarla, pero estas también la alteran para adecuarla al nuevo uso. Espacios culturales, en este tipo de usos seconsidera de manera casi inconsciente que existe una relación con la población y una mejora en la de calidad de vida, pero en muchos casos no se logra. En lo referente a la ganancia económica, esta es escasa o nula; además no se invierte mucho presupuesto para la intervención en restauración. Los espacios culturalesincluyen usos como: museo, centro de interpretación, casas de la cultura, centro cultural, biblioteca, etc. (Flores, 2016).

Ahora bien, si nos centramos en los espacios culturales para poner de relieve sus puntos débiles, podemos decir que existe un error al creer que el tipo de uso como espacio cultural tiene una relación inmediata con la población. Para evitar esto se debe tomar una actitud inclusiva y participativa con la los personas que viven en la localidad (Guadarrama, 2013). Otro punto débil del modelo de espacio cultural es su poca generación de ingresos, lo que a su vez puede repercutir en la falta de intervenciones para mantener la conservación de las construcciones debido a su alto costo; la forma de contrarrestar esto es la autosuficiencia económica a través de ingresos propios (boletería y otros servicios que se puedan dar a los visitantes) o el financiamiento por parte del sector privado.

Para el caso de México el uso más común para las haciendas, en el modelo de espacio cultural, es el museo, entre ellas podemos encontrar a las siguientes:

El Lencero se encuentra ubicada en el estado de Veracruz cerca de la ciudad de Xalapa, su construcción es del siglo XVI. En el año 1981, el estado de Veracruz adquiere la parte principal compuesta por 8 hectáreas y restaura su casa principal. Para el año de 1986 se funda en la casa hacienda un museo de antigüedades. Posteriormente se crearía un Patronato Autónomo que se hace cargo de la administración del museo (Calonge, 2011).

El Museo Casa de la Bola se localiza en el Distrito Federal de México en el barrio de Tacubaya; el origen de la hacienda se remonta al siglo XVI. El ultimo dueñoAntonio Haghenbeck y de la Lama la remodeló en 1940 y la acondicionó como una mansión del siglo XIX. A su muerte, en 1984, la donó a la fundación que lleva su nombre con el fin de conservarla y realizar actividades culturales y educativas. El 27 de mayo de 1991 fue una inaugurada como museo (Flores, 2016).

Nogueras se localiza en estado de Colima en el municipio de Comala, su construcción se remonta al siglo XVIII. El proyecto de restauración y adaptación para uso de museo es iniciado en 1995, en donde intervinieron los arquitectos Gabriel Gómez Azpeitia y Juan Castillo Parra, bajo la supervisión del maestro Alejandro Rangel (fue un artista y pintor mexicano), quien era dueño de la hacienda. El Museo es inaugurado el 16 de octubre del 1996. En el año 2000 con la muerte de Alejandro Rangel, la Universidad de Colima adquiere la hacienda y mantiene el uso de la casa hacienda como museo. En las salas del museo se exhibe piezas arqueológicas, artesanías, pinturas y dibujos (Conde, Schmidt y Covarrubias, 2014).

La Ferrería, se encuentra ubicada cerca de la ciudad de Durango en el Estado del mismo nombre. La casa hacienda fue construida en el siglo XIX y en 1986, el Estado de Durango la expropió. En el 1998 tras ser restaurada integralmente, fue fundado en la casa hacienda el 
«Museo de Arte Guillermo Ceniceros» (quien fue un pintor muralista mexicano). Su museografía fue diseñada por uno de los más importantes museógrafos mexicanos, Rodolfo Rivera. En la actualidad es el más relevante de los museos del Estado de Durango y uno de los más importantes del Norte de México (Irigoyen, 2011).

Canutillo, se encuentra ubicada en el Estado de Durango en el municipio de Ocampo, construida en del siglo XVIII. En la casa hacienda funciona un museo sobre la vida de Pancho Villa quien fuera uno de los jefes de la revolución mexicana de los años 1910 a 1920. Durante los últimos años la edificación se ha ido deteriorando (Villa, 2013).

La Loma se localiza en el Estado de Durango, en el municipio de Lerdo. Fue edificada en el siglo XIX. Desde el año de 1994 el complejo de la hacienda funciona como «Museo Francisco Villa y la División del Norte». Allí se exhibe una vasta colección de fotografías de la revolución mexicana (1910 a 1920) y objetos de la época. Los trabajos de restauración y remodelación se realizaron entre los años 2000 y 2001 (El Siglo de Torreón, 2013).

La Luz que se ubica en el Estado de Tabasco en la ciudad deComalcalco, fue construida en el siglo XIX. En la actualidad funciona en la hacienda el «Museo del Cacao y el Chocolate».Su extensión es de 2 hectáreas y se puede apreciar flora y fauna de la región. Se ha convertido en un punto turístico emblemático en el Estado de Tabasco, recibiendo más de 10,000 turistas al año (Camacho y Paz, 2015).

San Bernardo edificada a inicios del siglo XX, en el Estado de Yucatán en elmunicipio de Kopomá. Parte de su infraestructura funciona como museo de historia y antropología. Exhibe además, piezas arqueológicas de la Cultura Maya encontradas en diferentes partes de Yucatán, algunas de ellas halladas en los terrenos de la hacienda (Gobierno del Estado de Yucatán, 2017).

En lo que respecta a centros de interpretación, en México se pueden encontrar pocos ejemplos, entre ellos está el de Los Tovares que se localiza en el Municipio de Cadereyta de Montes en el Estado de Querétaro. La hacienda había sido edificada en el siglo XVII y a partir del año 2009 la casa hacienda fue sometida a un proceso de restauración para recuperar su forma original. En la actualidad funciona como centro de interpretación, además ofrece a los visitantes paseo en carruajes y servicio de restaurante. (El Universal, 2013). En otros países tenemos casos como los siguientes: En España, la Casa Hacienda Santa Cruz que fue construida a inicios del siglo XX, ubicada en el Municipio de la Rinconada en Sevilla, donde funciona el "Centro de Interpretación del Agua». En el Caribe, en la Isla Martinica, la Hacienda Clément, la cual tiene una mansión de finales del siglo XVIII; hoy en día funciona ahí el «Centro de Interpretación del Ron y del Patrimonio Industrial».

Sobre la experiencia mexicana y otras que se han tocado, podemos decir lo siguiente: La restauración no se vio como la meta final, sino que es parte de un proceso que busca darle un nuevo uso a la casa hacienda. Sobre esa base, ver la restauración como único fin en Punchauca es un error, debería seguirse el ejemplo de México y aprovechar la infraestructura de la casa hacienda para darle un uso contemporáneo en beneficio de la sociedad.

Los gobiernos de los estados mexicanos (semejante a nuestros gobiernos regionales) han mostrado una preocupación desde hace décadas por la preservación de este tipo de patrimonio, teniendo un papel activo, se ven casos de expropiación, compra y restauración. En el caso de Punchauca la iniciativa por parte del Estado se ha dado recién en los últimos años y aún no se concreta una restauración que devuelva las características que tenía antes la casa hacienda. 
Los casos mencionados no descontextualizan el bien, hay una preservación como conjunto (casa hacienda más el complejo) y en algunos casos se mantiene parte del entorno agrícola o natural. Cuando se mantiene la mayor parte de la hacienda es un beneficio a la hora de apuntar al turismo, pues son más las actividades que se pueden ofrecer a los visitantes. Además, mantener un entorno natural o agrícola es un atractivo que se le agrega a la arquitectura histórica que se apreciaría. En el Perú, el nivel de protección para patrimonio de haciendas solo se limita a la casa hacienda, entendiendo el bien de una manera descontextualizada y restringida. La zona de Punchauca en la actualidad está siendo lotizada, con el riesgo que en los próximos años la casa hacienda quede rodeada por construcciones modernas. Para evitar que toda la zona termine lotizada, se podría seguir los ejemplos mexicanos y ante la venta de las tierras, comprarlas de ser posible para mantener parte del entorno.

Respecto a la restauración y puesta en valor de las casas haciendas en México, se puede decir que se ha tenido un nivel de éxito. Sin embargo, en el uso de espacios culturales se tiene algunos puntos débiles, como son: no se tiende a lograr una relación entre la población y la casa hacienda, no existe una mejora en la calidad de vida del poblador, poca ganancia económica, no se invierte mucho presupuesto en la restauración. Ahora, en el uso de hotelería y turismo, los puntos débiles de espacios culturales como la generación de ingresos económicos son superados, además de haber una leve mejora económica e involucración de la población. La idea sería seguir siendo espacios culturales como museos o centro de interpretaciones, pero ser atractivos para el turista y de esta manera generar ingresos. En el caso de Punchauca al no haber un caso nacional similar, se tendría que tomar como referencia el mexicano, aprender de sus fortalezas y debilidades.

\section{Conclusiones}

El conocimiento que se tiene de la historia de la Hacienda Punchauca es limitado debido a que se cuenta con pocas fuentes primarias de información. Para poder profundizar en algunos temas específicos de esta se tendrá que recurrir al apoyo de otras ciencias que puedan brindar más datos.

En cuanto a la evolución arquitectónica de la Casa Hacienda Punchauca esta no se conoce con mucha claridad en fechas anteriores a fines del siglo XVIII; hace falta realizar más estudios que permitan datar el año de inicio de la construcción.

No hay una adecuada protección del bien. Se dieron resoluciones y decretos pero no hubo acciones reales hasta una época reciente. Además, la protección solo se limita y limitó a la casa hacienda, no tomando en cuenta el complejo agrario ni el entorno agrícola que en la actualidad están casi por desaparecer.

Es necesaria la intervención en la Casa Hacienda Punchauca, que no solo sea una restauración. Tiene que hacerse una puesta en valor del monumento con un modelo de gestión adecuado, para que se escoja el mejor uso al sitio y se incluya a la población local.

Se tendrá que dar medidas para evitar la desaparición del área agrícola que aún queda y ver la manera de incluir en el área declarada de la Casa Hacienda Punchauca estructuras antiguas que estén quedando fuera; además de evitar que el monumento reciba impacto físico y visual de las construcciones modernas.

\section{Bibliografía}

Arciga, R. (2016). Puesta en valor de las casas haciendas de Lima Norte. Consideraciones para la restauración. En SIPA, Actas y memorias del $5^{\circ}$ seminario internacional de patrimonio agroindustrial (pp. 363-373). Lima: Universidad Ricardo Palma. 
Caballero, L. (1995). Método para el análisis estratigráfico de construcciones históricas o "lectura de paramentos". Informes de la construcción, En Revista CSIC,46 (435):37-46. Madrid: Centro de Estudios Históricos-CSIC.

Cabezas, C. (2010). Guía Metodológica para la elaboración de modelos de gestión del patrimonio cultural Inmueble. Santiago: Ministerio del Interior-Subsecretaría de Desarrollo Regional y Administrativo.

Calonge, F. (2011). Otras formas de turismo patrimonial. El caso de las ex haciendas de Xalapa. Andamios, 8 (16): 261-286.

Camacho, M. y PazC. A. (2015). Desafíos del marketing en las haciendas cacaoteras de México. XIX Congreso Internacional de la Academia de Ciencias Administrativas A. C. (pp. 2-21). Durango: Academia de Ciencias Administrativas A. C.

Carbonara, G. (1998). Tendencias actuales de la restauración en Italia. En Loggia. Arquitectura \& restauración, 12 (23):13-23. Valencia: Universidad Politécnica de Valencia.

Cerdán, A. (1793). Tratado general sobre las aguas que fertilizan los valles de Lima. Lima-: Imprenta real de los niños expósitos

Conde, E. M.,Schmidt N. E. y Covarrubias R. (2014). La ruta del café Comala”: una opción para diversificar la actividad turística. Revista de investigaciones en turismo y desarrollo local, 7 (17): 1-13.

De Domingo, E. (2014). Los centros de interpretación históricos, artísticos y Arqueológicos en la Provincia de Burgos. Burgos: Universidad de Burgos.

El Siglo de Torreón (2013). Esperan distinción para Ex Hacienda La Loma. Recuperado en 1 de Julio de 2013 https://www.elsiglodetorreon.com.mx/ noticia/887372.esperan-distincion-para-ex-hacienda-la-loma.html

El Universal (2013). Los Tovares, un centro de interpretación. Recuperado en 11 de Noviembre de 2013 de http:// www.eluniversalqueretaro.mx/vida-q/11-09-2013/los-tovares-un-centro-de-interpretacion

Escudero, J. (1 de Febrero de 1820) Inventario físico de la casa, capilla de la antigua Hacienda de Punchauca. Protocolo 219. Archivo General de la Nación del Perú.

Espinoza, P. (7 de octubre de 1744). Remate de la Hacienda Santiago de Punchauca. Protocolo 304. Archivo General de la Nación del Perú.

Flores, L. G. (2016). Recuperación de cascos hacendarios en México. El ecomuseo como alternativa. Revista de El Colegio de San Luis 6 (11): 138-175.

Gobierno del Estado de Yucatán (2017). San Bernardo. Recuperado en 12 de Noviembre de 2017 de http://www. yucatan.gob.mx/?p=san_bernardo

Gonzáles, A. (2000). La restauración objetiva (Método SCCM de restauración monumental): Memoria SPAL 1993-1998. Barcelona: Diputación de España.

Guadrarrama, A. (2013). “Gestión del Patrimonio Cultural Municipal: entre la teoría y la praxis. El caso de la Ciudad de Tlacotalpan, Veracruz, a partir de su declaratoria como patrimonio Mundial de la Unesco"(Tesis de Licenciatura). México D.F., Universidad Nacional Autónoma de México.

Hayakawa, J. (2012). Restauro UNI, Breve antología de los textos de restauración del patrimonio monumental edificado. Lima: Universidad Nacional de Ingeniería.

Irigoyen, A. V. (21 de Mayo de 2011). Majestuosa edificación. El Siglo de Durango, p. 12.

Ludeña, H. (1973). Investigaciones arqueológicas en el sitio de Huacoy, Valle del Chillón (Tesis de Bachillerato). Lima: Universidad Nacional Mayor de San Marcos.

Muñoz, S. (2003). Teoría contemporánea de la restauración. Madrid: Editorial Síntesis S.A.

Pulgar, J. (1941). Las ocho regiones naturales del Perú. En Actas de la Tercera Asamblea General del Instituto Panamericano de Geografía e Historia (pp. 223-246). México D.F: Editorial Stylo.

Quispe, E. (2013). Hacia el Bicentenario del Perú. Año 2021. Un Enfoque Histórico de Lima Norte, El Caso de la Casa Hacienda Santiago de Punchauca. Lima: Universidad Católica Sedes Sapientiae.

Sandoval, A. (13 de mayo de 1803) Inventario físico de la casa, capilla de la antigua Hacienda de Punchauca. Protocolo 697. Archivo General de la Nación del Perú. 
Orellana, F. (1 de Septiembre de 1851) Inventario físico de la casa, capilla de la antigua Hacienda de Punchauca. Protocolo 481. Archivo General de la Nación del Perú.

Silva,J. (1998). Una aproximación al periodo Formativo en el valle del Chillón. Boletín de Arqueología, (2):251268). Lima: Pontificia Universidad Católica del Perú.

Tilden, F. (2006). La interpretación de nuestro patrimonio. Sevilla: Asociación para la interpretación del Patrimonio.

Vela, X. (2010). Glosario de Arquitectura.Quito: Instituto Nacional de Patrimonio Cultural del Ecuador.

Villa, G. (2013). La vida con Villa en la Hacienda Canutillo. Revista Bicentenario (7): 87-96.

Villa, M. (2016). Complejos agroindustriales azucareros de la Costa Norte Peruana. En SIPA, Actas y memorias del $5^{\circ}$ seminario internacional de patrimonio agroindustrial (pp. 255-273). Lima: Universidad Ricardo Palma.

Villar, P. E. (1935). Las culturas prehispánicas del departamento de Lima. Lima: Concejo Municipal de Lima.

Williams, C., Palacios, L., Pérez, L., Guerrero, D. y Palacios, J. (1989). Inventario del Patrimonio Monumental Inmueble, Valles del Chillón, Rímac y Lurín. Tomo II. Lima: Facultad de Arquitectura, Urbanismo y Arte. Universidad Nacional de Ingeniería - Fundación Ford.

\section{Otras referencias}

\section{Planoteca del Archivo General de la Nación del Perú}

- Plano de Carabayllo. Alto y Bajo Chillón (1893)

\section{Servicio Aerofotográfico Nacional del Perú}

Fotos aéreas:

- Foto aérea de la zona de Santa Rosa - San Martín de Porres (1945)

- Foto aérea de la zona de Punchauca - Carabayllo (1945)

Presentado: 22 junio 2017

Aceptado: 6 febrero 2018

Publicado online: 27 febrero 2018 
